\title{
Detection of Clostridium perfringens and its enterotoxin in cases of sporadic diarrhoea
}

\author{
M M Brett, J C Rodhouse, T J Donovan, G M Tebbutt, D N Hutchinson
}

\begin{abstract}
Aims: To determine the incidence of sporadic and apparently non-food related diarrhoea associated with Clostridium perfringens enterotoxin.

Methods: Enzyme linked immunosorbent assay (ELISA) and reversed phase latex agglutination (RPLA) were used to detect $C$ perfringens enterotoxin in faecal specimens from 818 sporadic cases of diarrhoea.

Results: $C$ perfringens enterotoxin was identified as a cause of sporadic diarrhoea in 56 of $818(6.8 \%)$ cases. Diarrhoea was prolonged (three days or more) in most cases. Ages ranged from 3 months to 89 years, although most patients were over 60 years of age.

Conclusions: These results suggest that $C$ perfringens may be a cause of sporadic cases of diarrhoea when causes such as food consumption or cross-infection are absent, particularly in the elderly.
\end{abstract}

The role of Clostridium perfringens and its enterotoxin in foodborne diarrhoea is well known. $C$ perfringens enterotoxin has also been implicated as a cause of antibiotic associated diarrhoea $^{1}$ and of diarrhoea by person to person transmission in hospital patients. ${ }^{2} \mathrm{~A}$ single case of sporadic diarrhoea associated with $C$ perfringens in a healthy adult with no apparent food association and no antibiotic treatment has also been reported. ${ }^{3}$

The aim of this survey was to determine the incidence of $C$ perfringens enterotoxin in sporadic cases of apparently non-food related diarrhoea in the general population.

\section{Methods}

The Public Health Laboratories at Ashford, Middlesbrough, and Preston examined all faecal specimens from isolated incidents of acute diarrhoeal illness received between September and December 1988. Samples were tested for the presence of $C$ perfringens and its enterotoxin as well as other stool pathogens (including $C$ difficile, Yersinia enterocolitica, salmonella, shigella, campylobacter and Rota viruses). Faecal specimens $(n=818)$ were obtained as soon as possible after symptoms began.

RPLA

One volume of faeces was mixed with two-four volumes of phosphate buffered saline (Oxoid
Dulbecco 'A', $\mathrm{pH} 7 \cdot 3$ ) and clarified by centrifugation at $12000 \times g$ for 20 minutes. The supernatant fluid was removed and passed through a $0.2 \mu \mathrm{m}$ membrane filter (Gelman Sciences Ltd, Northampton, England). Detection of enterotoxin using the RPLA kit was carried out as described previously. ${ }^{4}$ The RPLA kits used were of the same batch number and were supplied by Oxoid Limited, Basingstoke, England. A test sample was considered to be positive when a two well difference was observed between test and control agglutination. Positive extracts were referred to FHL for confirmation by ELISA.

ELISA

Polystyrene microtitre plates (High binding, Greiner) were coated overnight at $4^{\circ} \mathrm{C}$ with rabbit IgG against enterotoxin in $0.1 \mathrm{M}$ sodium carbonate buffer, $\mathrm{pH} \mathbf{9 \cdot 8}$. Unbound sites were blocked by $1 \%$ bovine serum albumin (BSA) (Sigma) in $0.1 \mathrm{M}$ sodium carbonate buffer, $\mathrm{pH} 9 \cdot 8$, incubated overnight at $4^{\circ} \mathrm{C}$.

Test extracts were incubated undiluted with $0.05 \%$ Tween 20 (Sigma) and after dilution 1 in 10 in PBS, $0.05 \%$ Tween 20 for 75 minutes at room temperature. Each extract was also incubated with neutralising antibody. After washing, rabbit anti-enterotoxin conjugated to horseradish peroxidase in PBS, $0.05 \%$ Tween $20,1 \%$ BSA was incubated for two hours at room temperature. The enzyme substrate solution contained $0.5 \mathrm{mg} / \mathrm{ml}$ orthophenyldiamine in citrate phosphate buffer $(2.43 \mathrm{ml} 0.1 \mathrm{M}$ citric acid, $2.57 \mathrm{ml} 0.2 \mathrm{M}$ sodium phosphate, and $5.0 \mathrm{ml}$ distilled water). The reaction was stopped by adding $100 \mu \mathrm{l} 4 \mathrm{M} \mathrm{H}_{2} \mathrm{SO}_{4}$ and the absorbance at $492 \mathrm{~nm}$ was read in a Titertek Multiskan MCC plate reader. Wells containing no absorbed antibody or no test extract were included in each plate and gave an absorbance of less than $0 \cdot 10$.

A standard curve on each plate was used to calculate the enterotoxin concentration. This covered the full range of absorbance with enterotoxin concentrations between $0.1 \mathrm{ng} / \mathrm{ml}$ and $100 \mathrm{ng} / \mathrm{ml}$.

The coefficient of variance $(100 \times$ standard deviation/mean) for intra-assay measurement of enterotoxin concentration was $2-5 \%$. The coefficient of variation of interassay measurements of enterotoxin concentration was between $4.4 \%$ and $11 \cdot 2 \%$.

$C$ perfringens spore counts were determined following alcohol shock. ${ }^{5}$ Pure cultures of $C$ perfringens isolated from enterotoxin positive faeces were sent to the PHLS Food Hygiene Laboratory for serological typing using a set of 
Table 1 Concentration of enterotoxin detected in faecal samples

\begin{tabular}{cllll}
\hline & $\begin{array}{l}\text { Sporadic diarrhoea } \\
\text { without antibiotic } \\
\text { treatment }\end{array}$ & $\begin{array}{l}\text { Sporadic diarrhoea } \\
\text { with antibiotic } \\
\text { treatment }\end{array}$ & Food poisoning* \\
\cline { 2 - 3 } Number (\%) & Number (\%) & Number (\%) \\
\hline $1-10$ & $3(6)$ & 0 & $18(11 \cdot 5)$ \\
$11-100$ & $6(13)$ & $3(33)$ & $27(17)$ \\
$101-1000$ & $10(21)$ & $3(33)$ & $23(15)$ \\
$1001-10,000$ & $20(43)$ & 0 & $52(33)$ \\
$10,001-100,000$ & $8(17)$ & 0 & $28(18)$ \\
\hline 100,001 & $0(0)$ & $9(6)$ & \\
\hline
\end{tabular}

${ }^{\star}$ Food poisoning results are those of Bartholomew et $\mathrm{al}^{4}{ }^{7}$

Table 2 Spore count of enterotoxin positive faeces

\begin{tabular}{lll}
\hline & \multicolumn{2}{l}{ Number of patients } \\
\cline { 2 - 3 } Spore count/g faeces & No antibiotics & Antibiotics \\
\hline$<10^{2}$ & 8 & 6 \\
$10^{3}$ & 1 & 0 \\
$10^{4}$ & 1 & 0 \\
$10^{5}$ & 2 & 1 \\
$10^{6}$ & 3 & 1 \\
$\geqslant 10^{7}$ & 24 & 1 \\
\hline
\end{tabular}

Table 3 Relation between age and faecal spore count of $C$ perfringens

\begin{tabular}{llc}
\hline & \multicolumn{2}{l}{ Spore count } \\
\cline { 2 - 3 } & $\leqslant 10^{5} / g$ & $>10^{5} / g$ \\
\hline No antibiotic treatment: & 9 & 7 \\
$\quad<60$ years & 0 & 24 \\
$\quad$ Antibiotic treatment: & 3 & 0 \\
$\quad<60$ years & 1 & 2 \\
\hline 60 years & & \\
\hline
\end{tabular}

Table 4 Age distribution of patients with enterotoxin positive faeces

\begin{tabular}{lll}
\hline & \multicolumn{2}{l}{ Number of patients } \\
\cline { 2 - 3 } Age/years & No antibiotics & Antibiotics \\
\hline $0-10$ & 3 & 0 \\
$11-20$ & 2 & 1 \\
$21-30$ & 3 & 0 \\
$31-40$ & 4 & 0 \\
$41-50$ & 4 & 2 \\
$51-60$ & 4 & 1 \\
$61-70$ & 4 & 2 \\
$71-80$ & 15 & 1 \\
$81-90$ & 9 & 1 \\
\hline
\end{tabular}

143 antisera. $^{6}$

A questionnaire was completed for every RPLA positive specimen by the general practitioner or hospital doctor as appropriate, in an attempt to determine whether various factors were involved. These included antibiotic treatment, other medication (drugs, enemas, laxatives) and the possibility of food association (including consumption of a poultry or meat dish within the previous 24 hours).

\section{Results}

Every acute diarrhoeal stool specimen received during the four month period which was not part of an outbreak was screened for $C$ perfringens enterotoxin with the Oxoid RPLA kit. A positive reaction occurred in 75 of 818 (9.2\% samples). A different enteropathogen ( $Y$ enterocolitica, $C$ difficile, salmonella, campylobacter) was isolated from 11 of the 75 enter- otoxin positive faeces and these were excluded from further analysis.

The presence of $C$ perfringens enterotoxin was confirmed by ELISA in 56 of 64 cases, with concentrations between $7 \mathrm{ng} / \mathrm{g}$ faeces and $25.6 \mu \mathrm{g} / \mathrm{g}$ faeces (table 1). These concentrations are comparable with those found in specimens from food poisoning outbreaks (table 1). Nine of the 56 enterotoxin positive patients were taking antibiotics and none had any known food association.

$C$ perfringens spore counts were estimated in 39 of 47 enterotoxin positive patients who were not taking antibiotics (table 2). Most patients had high spore counts: more than $10^{5} / \mathrm{g}$ in $74 \%$ (33 of 39) and above $10^{7} / \mathrm{g}$ in $62 \%$ ( 25 of 39 ). Spore counts were $10^{5} / \mathrm{g}$ or more in 21 of 42 (50\%) age matched control faecal specimens. All 24 diarrhoeal samples from patients 60 years or older, but only half the samples from patients aged less than 60 had spore counts of more than $10^{5} / \mathrm{g}$. Spore counts of more than $10^{5} / \mathrm{g}$ were found in $58 \%$ (15 of 26 ) control patients aged older than 60 years and $27 \%$ (six of 22) in those under 60 years. Six of the nine patients with diarrhoea taking antibiotics had spore counts of less than $800 / \mathrm{g}$ faeces, while the other three had counts of $3 \times 10^{5}$, $9.5 \times 10^{5}$, and $1 \times 10^{8} / \mathrm{g}$ (table 2).

$C$ perfringens isolates from 40 patients were serotyped. In a total of 53 strains there were 21 different serotypes and a number of isolates which were non-typable, auto-agglutinating, or which gave non-specific agglutination. There was no common serotype overall, but in two separate instances there was a cluster of the same serotype in two and three patients, respectively, from the same hospital ward, although symptoms developed over a period of two weeks.

There was no significant difference in the number of enterotoxin positive cases between males and females (30 and 26, respectively) and in the number in the community or hospital (26 and 30, respectively). The age range of patients was 3 months to 89 years, with a mean of 59.4 years, but 33 of $48(69 \%)$ were over 60 (table 4 ). The age of 56 patients with enterotoxin negative sporadic diarrhoea ranged from 1 year to 97 years with a mean of 47 years. Only $36 \%$ (20 of 56 ) were aged 60 years or more.

The duration of diarrhoea was one to two days in 11 of 40 cases and three to 21 days in 29 of 40 cases. There was no correlation between either spore count or enterotoxin concentration and duration of diarrhoea, but diarrhoea of three days or more occurred more frequently in patients aged 60 years or more (14 of 21) than in those aged under 60 (two of 11).

\section{Discussion}

$C$ perfringens enterotoxin was the only significant finding in $6.8 \%$ of the 818 cases of sporadic diarrhoea examined in this survey. The range of concentrations of enterotoxin detected in this survey were similar to those reported in classic food poisoning out- 
breaks. $^{47}$

Only half the patients with diarrhoea aged under 60 had spore counts of more than $10^{5} / \mathrm{g}$. This is in contrast to outbreaks of $C$ perfringens food poisoning, where a spore count of $10^{5} / \mathrm{g}$ is regarded as one criterion for diagnosis. ${ }^{8}$ Spore counts were high $\left(>10^{5} / \mathrm{g}\right)$ in all patients with diarrhoea aged 60 years or more, but carriage of high numbers of $C$ perfringens can occur in the absence of diarrhoea in people of this age group. $^{89}$ These findings suggest that spore count should be interpreted with caution and that the presence of enterotoxin may be more informative.

A further important difference from classic food poisoning was the duration of diarrhoea. In almost half the cases of sporadic diarrhoea it lasted for seven days or more; in food poisoning it normally resolves within 12 to 24 hours. Diarrhoea longer than two days has been reported in other studies of antibiotic associated and infectious diarrhoea. ${ }^{10}$ It is not clear why diarrhoea is prolonged; there was no difference in spore counts or enterotoxin concentration between patients with and without prolonged diarrhoea. The patient's intestinal flora or immune system could be altered in such a way as to permit proliferation of enterotoxigenic $C$ perfringens.

Among the 56 enterotoxin positive faeces, there were two instances in separate geriatric wards where faecal samples from three and two patients, respectively, who were in the same geriatric ward yielded the same serotype, although the onsets of diarrhoea were one to two weeks apart. A similar finding has been reported, ${ }^{2}$ where the epidemiological evidence suggested that transmission of the causative organism was either by direct person to person contact or via a common environmental source.

A further nine $(16 \%)$ patients with enterotoxin positive faeces had received antimicrobial treatment, which has been associated with $C$ perfringens diarrhoea. ${ }^{1}$ The remaining 39 cases were not associated with antibiotic treatment or with a known outbreak of food poisoning, although a single point source of foodborne organisms cannot be precluded.

These findings confirm and extend those of Larson and Borriello in a survey of sporadic diarrhoea in 50 hospital patients, $1.5 \%$ of whom were shown to contain $C$ perfringens enterotoxin in their faeces by a Vero cell assay.
Most enterotoxin positive patients were treated with antibiotics. ${ }^{10}$ The results of our study show that sporadic diarrhoea occurs in the community as well as in hospital patients and is not confined to patients receiving antibiotics. We also found that a higher proportion of cases of sporadic diarrhoea were enterotoxin positive. This may be because ELISA is a much more sensitive technique than Vero cell assay. ${ }^{4}$

It is known that sporadic diarrhoea can be caused by other enteropathogens, such as salmonella and $C$ difficile, both with and without antibiotic treatment. The results presented here show that sporadic diarrhoea can also be caused by $C$ perfringens enterotoxin, in both hospital patients and in the community, in the absence of antibiotic treatment and with no known food association. Sporadic diarrhoea differed from classic food poisoning in the duration of diarrhoea, which was frequently prolonged, and in being more common in the elderly. The findings suggest that diagnostic laboratories should perhaps consider screening for $C$ perfringens enterotoxin in cases of sporadic diarrhoea, particularly in elderly patients.

We are very grateful to Oxoid Ltd for their generous donation of the RPLA kits.

1 Borriello SP, Larson HE, Welch AR, Barclay F, Stringer MF, Bartholomew BA. Enterotoxigenic Clostridium perfringens: a possible cause of antibiotic associated diarrhoea Lancet 1984; i:305-6.

2 Borriello SP, Barclay FE, Welch AR, et al. Epidemiology of Diarrhoea caused by enterotoxigenic Clostridium perfringens. $\mathcal{F}$ Med Microbiol 1985;20:363-72.

3 Luzzi I, Caprioli A, Bisicchia R, Ciammarugh R, Mastrantonio P. A sporadic case of diarrhoea due to enterotoxigenic Clostridium perfringens. Microbial Ecology in Health and Disease 1988;1:69-70.

4 Berry PR, Rodhouse JC, Hughes S, Bartholomew BA Gilbert RJ. Evaluation of ELISA, RPLA and Vero cell assays for detecting Clostridium perfringens enterotoxin assays for detecting Clostridium perfringens entero
in faecal specimens. $f$ Clin Pathol 1988;41:458-61.

5 Koransky SR, Allen SD, Dowell VR. Use of ethanol for selective isolation of spore forming micro-organisms. Appl Environ Microbiol 1978;35:762-5.

6 Hughes JA, Turnbull PCB, Stringer MF. A serotyping system for Clostridium welchii (Clostridium perfringens) type $A$, and studies on the Type-Specific antigens. $\mathcal{F} \mathrm{Med}$ Microbiol 1976;9:475-85.

7 Bartholomew BA, Stringer MF, Watson GN, Gilbert RJ. Development and application of an enzyme linked immunosorbent assay for Clostridium perfringens type nosorbent assay for Clostridium perfring

8 Stringer MF, Watson GN, Gilbert RJ, Wallace JG, Hassall $\mathrm{JE}$, et al. Faecal carriage of C perfringens. F Hyg Camb 1985;85:277-88.

9 Yamagishi T, Serikawa T, Morita R, Nakamura S, Nishida S. Persistent high numbers of Clostridium perfringens in the intestines of Japanese aged adults. $\mathcal{F p}_{\boldsymbol{n}} \boldsymbol{f}$ Microbio 1976;20:397-403.

10 Larson HE, Borriello SP. Infectious diarrhoea due to Clostridium perfringens. $\mathcal{F}$ Infect Dis 1988;157:390-1. 